\section{Clinical Manifestations of Neurosarcoidosis in the Netherlands}

\section{Abstract}

Background: Neurosarcoidosis is a rare disease. We investigated the prevalence of different manifestations of neurosarcoidosis and the influence of race or gender in the Netherlands, as well as the treatment strategies for neurosarcoidosis patients.

Methods: Multicentre observational cohort study of patients with neurosarcoidosis in two tertiary referral centres; the ILD Center of Excellence of the St. Antonius Hospital, Nieuwegein and the Amsterdam University Medical Centre (UMC), the Netherlands, from 2015 till 2017, as well as participants of the Dutch Neurosarcoidosis Registry between June 2014 and December 2017.

Results: A total of 194 patients were included, 27 of whom were in the Dutch Neurosarcoidosis Registry, 70 treated at the ILD Center of Excellence and 97 treated at the Amsterdam UMC. Of the 194 patients included, 54\% were female. The most common neurosarcoidosis manifestations were chronic meningitis (41\%), cranial nerve dysfunction (39\%), myelopathy (28\%) and cerebral parenchymal disease (26\%). Age, gender and race did not differ for the various manifestations, except for peripheral polyneuropathy, which was more prevalent in men than in women ( $21 \%$ versus $10 \%)$. Most neurosarcoidosis patients were treated with prednisone (89\%), methotrexate $(46 \%)$ or infliximab (21\%). A total of 102 patients $(53 \%)$ received second- or third-line treatment.

Conclusion: In a large cohort of neurosarcoidosis patients, chronic meningitis, cranial nerve dysfunction, spinal cord involvement and cerebral parenchymal disease were the most common manifestations. Age, race and gender did not influence the clinical presentation, except for peripheral polyneuropathy (men>women). Over half of the patients required multiple immunosuppressive treatments.

Keywords: Neurosarcoidosis; Manifestations; Gender; Race; Treatment

Received: February 11, 2019; Accepted: February 24, 2019; Published: February 28, 2019

\section{Introduction}

Sarcoidosis is a multisystem inflammatory disorder of unknown aetiology in genetically predisposed individuals [1-3]. The hallmark of sarcoidosis is granulomatous inflammation in the organs involved [4]. The natural history and prognosis of sarcoidosis are highly variable, and its course is often unpredictable [5-7]. Sarcoidosis most often affects the lungs and lymph nodes, though any other organ system can be involved [8].

Involvement of the nervous system, or neurosarcoidosis, is
Mareye Voortman ${ }^{1,2,3^{*}}$, Daan Fritz ${ }^{4}$, Oscar J.M. Vogels ${ }^{5}$, Diederik Van De Beek ${ }^{4}$, Jolanda De Vries ${ }^{3,6,7}$, Matthijs C. Brouwer" Marjolein Drent ${ }^{1,3,8, \#}$

1 ILD Center of Excellence, Department of Pulmonology, St. Antonius Hospital, Nieuwegein, The Netherlands

2 Department of Pulmonology, Division of Heart \& Lungs, University Medical Centre Utrecht, The Netherlands

3 ILD Care Foundation Research Team, Ede, The Netherlands

4 Department of Neurology, Amsterdam University Medical Centre, University of Amsterdam, Amsterdam Neuroscience, The Netherlands

5 ILD Center of Excellence, Department of Neurology, St. Antonius Hospital, Nieuwegein, The Netherlands

6 Department of Medical Psychology, ETZ Hospital (Elisabeth-TweeSteden Ziekenhuis), Tilburg, Tilburg, The Netherlands

7 Department of Medical and Clinical Psychology, Tilburg University, Tilburg, The Netherlands

8 Department of Pharmacology and Toxicology, FHML, Maastricht University, Maastricht, The Netherlands

\# Contributed equally

*Corresponding author: Dr. Mareye Voortman

झm.voortman@umcutrecht.nl

ILD Center of Excellence, Department of Pulmonology, St. Antonius Hospital, PO Box 2400, 3430 VB Nieuwegein, The Netherlands.

Tel: +31887574379

Citation: Voortman M, Fritz D, Vogels OJM, Beek DVD, Vries JD, et al. (2019) Clinical Manifestations of Neurosarcoidosis in the Netherlands. J Neurol Neurosci Vol.10 No.02:292. 
detected in $5 \%$ of cases during life, [9-12] although autopsy studies have shown neurologic involvement in $25-50 \%[13,14]$. Currently, the classification by Marangoni et al.[15], including definite, probable and possible neurosarcoidosis is used. Neurosarcoidosis can involve any part of the nervous system, causing a variety of neurological symptoms. A meta-analysis showed that the most common manifestations of neurosarcoidosis were cranial nerve dysfunctions and myelopathy $[16,17]$. Since neurologic involvement is the first presenting symptom in $50-70 \%$ of the neurosarcoidosis patients, and $52 \%$ of the patients have isolated neurosarcoidosis without systemic involvement [18-22], it can be difficult to diagnose. This might explain why previous studies reported variable prevalence of different manifestations $[3,19,23$ 26].

The influence of race on the epidemiology of sarcoidosis is generally recognized. The incidence of sarcoidosis in patients of African descent is high compared to that in Caucasians [27]. Moreover, they often present with more severe organ involvement, a worse prognosis and higher mortality rates than Caucasians [27-29]. It has also been acknowledged that the prevalence of various organ manifestations differs between different ethic subgroups, e.g. cutaneous and ocular sarcoidosis is more common in patients of African descent than in Caucasians, while hypercalcemia is more common in Caucasians [10]. In terms of gender differences, pulmonary and cardiac sarcoidosis is more common in men, whereas more peripheral lymph node involvement, cutaneous, ocular and liver sarcoidosis are seen more often in women $[10,30]$. To the best of our knowledge, racial and gender differences have so far not been studied specifically in neurosarcoidosis.

The aim of this study was to assess the prevalence of different manifestations of neurosarcoidosis and examine whether they vary with race and/or gender. In addition, the treatment strategies used for neurosarcoidosis patients were studied.

\section{Materials and Methods}

\section{Study design}

In this multicentre study, all neurosarcoidosis patients evaluated and/or treated between 2015 and 2018 were included. Furthermore, patients participating in the Dutch Neurosarcoidosis Registry between June 2014 and 2018 were included. All patients with neurosarcoidosis in the Netherlands had been invited to join the Dutch Neurosarcoidosis Registry, an online registration study [31]. Curavista (a certified eHealth platform) provided the online platform for this study and maintained the website. The present study was performed in accordance with the Declaration of Helsinki and its amendments. The patient registry and study protocol have been approved by the Medical Ethical Committee of the St. Antonius Hospital Nieuwegein. Digital or written informed consent was obtained from all patients.

\section{Study sample}

The overall study sample was comprised of patients from the ILD Center of Excellence of the St. Antonius Hospital Nieuwegein, and the Amsterdam University Medical Centre (UMC), the Netherlands, and the online Dutch Neurosarcoidosis Registry.
We carefully checked for overlap in registrations between the different sources.

At the ILD Center of Excellence and the Amsterdam UMC, patients were identified by their treating physician and data were extracted from medical records, de-identified and collected in a database. Patients in the Dutch Neurosarcoidosis Registry had either been identified and entered by their physician with their consent or joined the online registry of their own accord. Data in the registry were self-reported by patients. Additional medical data were requested from their treating physician(s) and data were checked to see if the diagnosis of neurosarcoidosis had been confirmed. Curavista (a certified eHealth platform) collected the data online and exported de-identified data to a database. All patients participating in the Dutch Neurosarcoidosis Registry had sufficient command of Dutch and had access to the internet.

Multiple diagnostic criteria have been proposed for neurosarcoidosis. In this population, neurosarcoidosis was diagnosed according to the classification system by Zajicek, later modified by Marangoni, which labels patients as definite, probable or possible neurosarcoidosis [15,22]. Definite neurosarcoidosis was diagnosed in case of a clinical presentation suggestive of neurosarcoidosis with exclusion of other possible diagnoses and the presence of positive nervous system histology. Probable neurosarcoidosis was diagnosed in case of a clinical presentation suggestive of neurosarcoidosis with MRI, CSF, and/ or EMG/NCS findings typical of granulomatous inflammation of the nervous system and after rigorous exclusion of other causes and evidence for systemic sarcoiodosis. Possible neurosarcoidosis was diagnosed in case of a clinical presentation suggestive of neurosarcoidosis with exclusion of alternative diagnosis where the above criteria are not met.

Patients with solely small fiber neuropathy (SFN) without granuloma formation in the affected tissue due to sarcoidosis were not considered to have neurosarcoidosis [32] and were excluded from this study ( $\mathrm{N}=50$, Dutch neurosarcoidosis registry). Myopathy was also excluded from this analysis.

\section{Data collection and definition of phenotypes}

Demographic and clinical data were extracted from medical records. Onset of sarcoidosis and neurosarcoidosis and their various manifestations were also recorded.

In order to determine associations between the various manifestations (systemic and neurosarcoidosis manifestations), we categorized neurosarcoidosis manifestations into 3 subgroups depending on anatomic location and severity.

Group 1: Peripheral polyneuropathy;

Group 2: Spinal cord manifestations (myelitis and polyradiculitis); and

Group 3: Cerebral parenchymal lesions, neuro-endocrine, and brainstem involvement, cerebral infarction, chronic aseptic meningitis, hydrocephalus and cranial nerve manifestations.

\section{Statistical analysis}

All statistical analyses were performed using SPSS version 24. 
Table 1 Summary of the overall characteristics of the Dutch neurosarcoidosis sample studied, subdivided by gender.

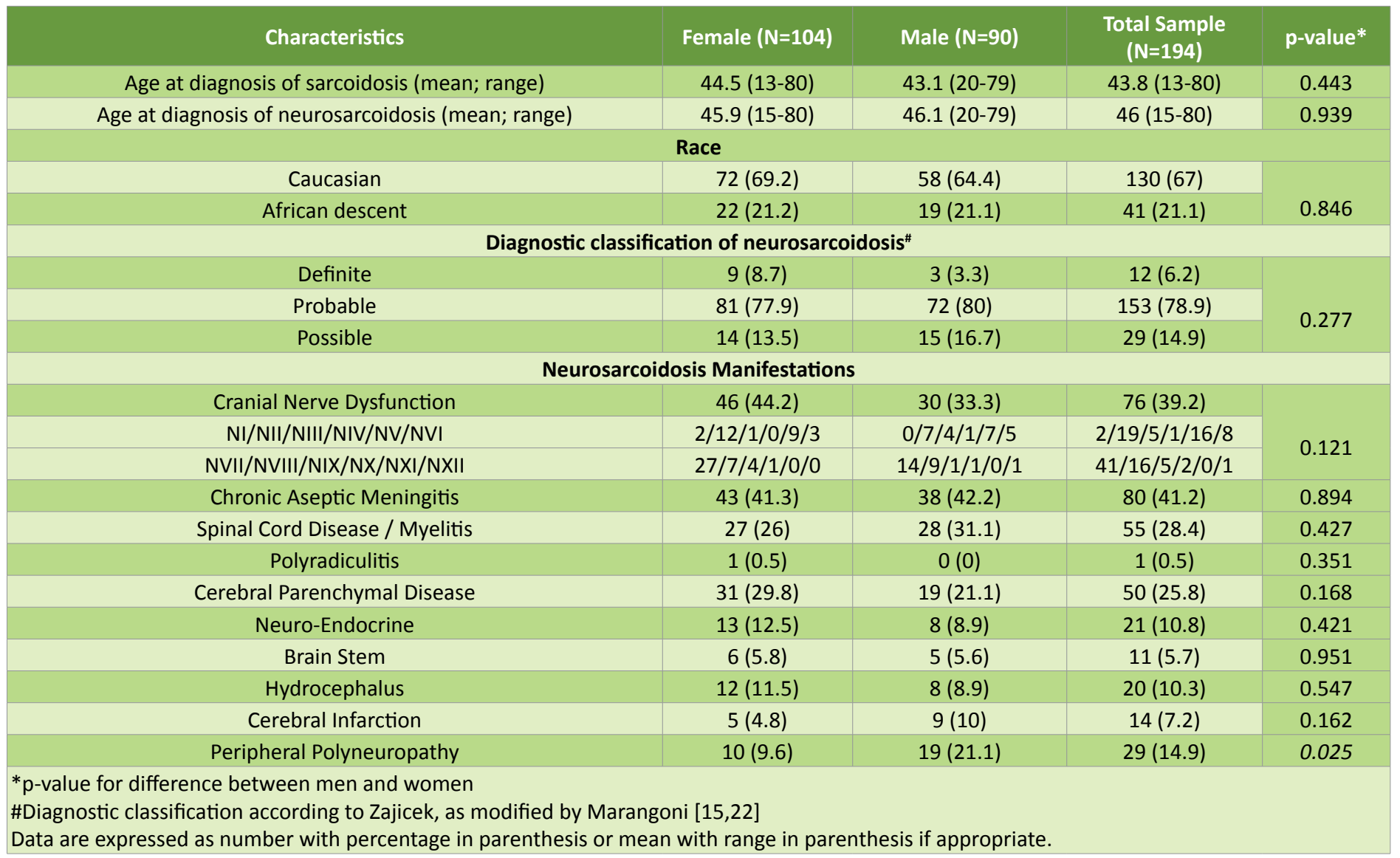

Data are presented as the means and range for continuous variables and as the number and percentage for categorical variables. In the analysis concerning race, we only compared Caucasians and patients of African descent, since other races were underrepresented, and groups were therefore too small to analyse.

Differences between genders and races were analysed using the Chi-square test for dichotomous variables and the MannWhitney-U test for continuous variables. Differences between the various neurosarcoidosis groups were analysed using the Chi-square test for dichotomous variables and Kruskal-Wallis tests for continuous variables. A p-value of $<0.05$ was considered statistically significant.

\section{Results}

From the data sources 194 patients with neurosarcoidosis were identified: 27 participated in the Dutch Neurosarcoidosis Registry, 70 were recruited by the ILD Center of Excellence and 97 patients by the Amsterdam UMC. Demographic data are summarized in Table 1. Twelve patients (6\%) were classified as definite neurosarcoidosis, 153 patients (79\%) as probable neurosarcoidosis and 29 patients (15\%) as possible neurosarcoidosis. Ten patients (5\%) had an isolated neurosarcoidosis without systemic manifestations.

The most common manifestations of neurosarcoidosis were chronic meningitis (41\%), cranial nerve dysfunction (39\%), spinal cord involvement (28\%) and cerebral parenchymal disease (26\%)
(Table 1). Cerebral parenchymal disease varied from white matter lesions (48\%) to intracerebral lesions with mass effect $(30 \%)$ and intracerebral nodules (24\%). Multiple neurosarcoidosis manifestations occurred simultaneously in 109 patients (56\%).

Treatment for neurosarcoidosis had been initiated in 181 patients $(93 \%)$, of whom 173 patients (89\%) with prednisone. Secondline treatment had been given to 121 patients (62\%), 89 of whom had been treated with methotrexate (46\%), 24 patients with azathioprine (12\%), five patients with mycophenolate mofetil (3\%), two patients with cyclophosphamide (1\%) and one patient with cyclosporine $(0.5 \%)$. Third-line treatment had been started in 44 patients (23\%), 40 of whom had been treated with infliximab (21\%) and four with adalimumab (2\%). Of the 13 patients $(7 \%)$ for whom no treatment had been initiated, six had shown spontaneous regression, while one had stable disease for years, three had no symptoms and three refused treatments. Patients with a facial nerve palsy as the only manifestation of neurosarcoidosis had mostly received prednisone ( 6 out of 7 cases). In 11 out of 20 cases with a hydrocephalus neurosurgical intervention was necessary (55\%).

A mortality rate of $2.1 \%$ was found in this cohort (four patients). The cause of death was neurosarcoidosis in two patients (hydrocephalus and cerebral lesions, respectively), infection due to immunosuppression in one patient and unknown cause in one patient.

No gender differences were found for the various neurosarcoidosis manifestations, except for peripheral polyneuropathy, which appeared to be more prevalent in men than in women $121.1 \%$ versus $9.6 \%$, $p=0.025$; Table 1). We found no significant differences 
Table 2 Various neurosarcoidosis manifestations subdivided by race.

\begin{tabular}{|c|c|c|c|}
\hline Neurosarcoidosis manifestation & Caucasian ( $\mathrm{N}=130)$ & African descent ( $\mathrm{N}=41)$ & p-value* \\
\hline Cranial nerve dysfunction & $51(39.2)$ & $18(43.9)$ & \multirow{3}{*}{0.595} \\
\hline NI/NII/NIII/NIV/NV/NVI & $2 / 13 / 4 / 1 / 8 / 6$ & $0 / 4 / 1 / 0 / 3 / 1$ & \\
\hline NVII/NVIII/NIX/NX/NXI/NXII & $26 / 13 / 3 / 2 / 0 / 1$ & $9 / 1 / 1 / 0 / 0 / 0$ & \\
\hline Spinal cord disease / myelitis & $39(30)$ & $10(24.4)$ & 0.489 \\
\hline Cerebral parenchymal disease & 35 (26.9) & $11(26.8)$ & 0.991 \\
\hline Hydrocephalus & $14(10.8)$ & $5(12.2)$ & 0.800 \\
\hline Cerebral infarction & $9(6.9)$ & $4(9.8)$ & 0.551 \\
\hline Peripheral neuropathy & $21(16.2)$ & $6(14.6)$ & 0.816 \\
\hline
\end{tabular}

Table 3 Treatment for different groups of neurosarcoidosis manifestations.

\begin{tabular}{|c|c|c|c|}
\hline & Group 1 ( $N=29)$ & Group 2 (N=56) & Group 3 (N=155) \\
\hline Prednisone & $26(90)$ & 51 (91) & $140(90)$ \\
\hline Methotrexate & $20(69)$ & $30(54)$ & $65(42)$ \\
\hline Azathioprine & $4(14)$ & $5(9)$ & $21(14)$ \\
\hline Mycophenolate mofetil & $0(0)$ & $3(5)$ & $4(3)$ \\
\hline Cyclosporine & $0(0)$ & $0(0)$ & $1(0.6)$ \\
\hline Cyclophosphamide & $0(0)$ & $1(2)$ & $1(0.6)$ \\
\hline Infliximab & $7(24)$ & $16(29)$ & $32(21)$ \\
\hline Adalimumab & $0(0)$ & $0(0)$ & $4(3)$ \\
\hline
\end{tabular}

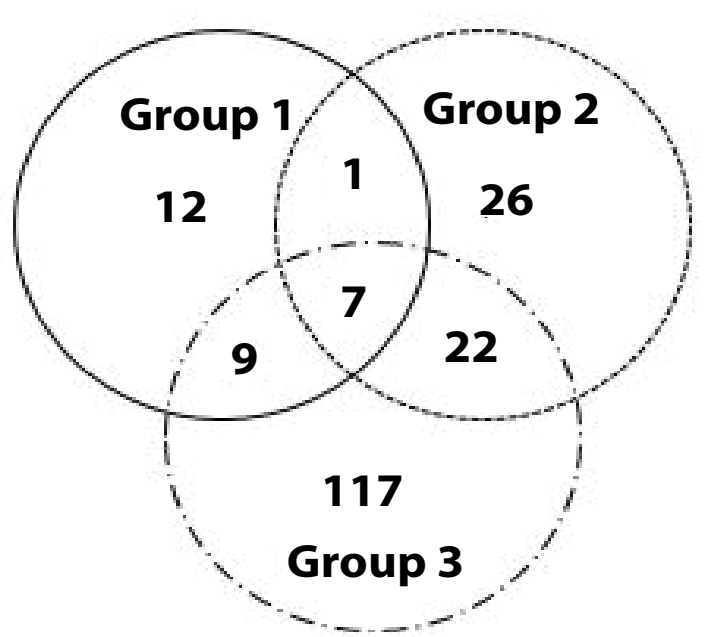

Figure 1 Venn diagram of manifestations from different neurosarcoidosis categories (Group 1: Polyneuropathy, Group 2: Spinal cord involvement and Group 3: Cerebral involvement).

between the two races regarding the various neurosarcoidosis manifestations (Table 2).

\section{Various categories of neurosarcoidosis}

The total neurosarcoidosis sample was subdivided according to the various manifestations. Group 1 (peripheral polyneuropathy) comprised of 29 patients, 10 women and 19 men $(p=0.025)$. Group 2 (spinal cord manifestations [myelitis and polyradiculitis]) comprised of 56 patients, 28 women and 28 men (not significant). Group 3 (cerebral parenchymal lesions, neuro-endocrine, cerebral infarction and brainstem involvement, chronic aseptic meningitis, hydrocephalus and cranial nerve manifestations) comprised of 155 patients, 90 women and 65 men $(p=0.012)$. No significant differences between these groups were found regarding age at time of diagnosis of sarcoidosis. Age at time of diagnosis of neurosarcoidosis was significantly different $(p=0.001)$; patients in group 3 were younger than patients in group 1 and 2 (44 years versus 51 and 48 years, respectively).

Thirty-nine patients presented with neurosarcoidosis manifestations from more than one category (Figure 1). There were seven patients with neurosarcoidosis manifestations from all three categories.

\section{Group 1: Polyneuropathy}

Hypercalcaemia was seen more frequently in patients with group 1 manifestations than in the other two groups (14\% vs $2 \%, p=0.006)$. Patients with polyneuropathy had less cerebral involvement ( $7 \%$ vs $29 \%, p=0.01$ ). Regarding treatment, patients with polyneuropathy were more often treated with methotrexate than patients in groups 2 and 3 (69\% vs 42\%, $p=0.007$ ) (Table 3 ).

\section{Group 2: Spinal cord disease}


Peripheral lymph node involvement was observed more frequently (93\% vs $79 \%, p=0.02$ ) in this subgroup compared to group 1 and 3. No neuro-endocrine or cerebrovascular involvement was observed in patients with spinal cord manifestations $(p=0.002$ and $p=0.015$, respectively). Cranial nerve dysfunction and chronic aseptic meningitis were also less common among patients with manifestations in this group $(19.6 \%$ vs $47.1 \%, p=<0.001$ and $27.7 \%$ vs $47.8 \%, p=0.011$, respectively). By contrast, there was more brainstem involvement ( $11.1 \%$ vs $3.6 \%, p=0.045)$. Infliximab had been started in a relatively high proportion of patients with manifestations in this group compared to the other categories, although this difference was not significant ( $29 \%$ vs $17 \%, p=0.07$ ) (Table 3).

Group 3: Cerebral parenchymal lesions, neuro-endocrine, and brainstem involvement, cerebral infarction, chronic aseptic meningitis, hydrocephalus and cranial nerve manifestations

No differences in systemic manifestations were observed between group 3 patients and the rest (Group 1 and 2). Patients with manifestations in this group had less frequently received treatment with methotrexate ( $42 \%$ vs. $62 \%, p=0.03)$ compared to the other groups (Table 3 ). Adalimumab was only given to patients in this group $(\mathrm{N}=4)$.

\section{Discussion}

This study has been one of the few neurosarcoidosis cohort studies so far and was performed in two Dutch national expertise centres and a national neurosarcoidosis database. Both expertise centres showed similar results in terms of prevalence of the manifestations. The most common neurosarcoidosis manifestations were chronic aseptic meningitis (42\%), cranial nerve dysfunction (39\%), spinal cord involvement (28\%) and cerebral parenchymal disease (26\%). Strikingly, much overlap was found in manifestations, with $56 \%$ of patients having two or more manifestations simultaneously. Over $90 \%$ of patients needed treatment.

The clinical presentation of neurosarcoidosis is known to be heterogeneous [18]. The disorder is hard to recognize due to its heterogeneity and rarity. We also found this diversity of clinical presentations in our Dutch cohort of neurosarcoidosis patients. We report a higher prevalence of meningitis, viz. $41 \%$, versus $16 \%$ reported in a meta-analysis [9]. This could probably be explained by the fact that both centres in our study are tertiary referral centres (inclusion bias). The Amsterdam UMC is also a referral centre for inflammatory and infectious meningitis. We also found more spinal cord involvement ( $28 \%$ versus $18 \%$ ) [9]. These manifestations are found in severely affected neurosarcoidosis patients, which is the main reason for referral. By contrast, we found less cranial nerve involvement (39\% versus 55\%) [9], with the facial, optic, trigeminal and vestibulocochlear nerves as the most commonly involved nerves. It is highly likely that these differences can be explained by the small sample sizes and mainly retrospective design of these previous studies [9], and by the tertiary setting of our neurosarcoidosis population. A comparison between our results and those reported from other referral centres showed that results were similar $[16,24,33]$. The prevalence of peripheral polyneuropathy in our study was comparable to that reported in a large meta-analysis [9]. Race and gender distributions in our total cohort of neurosarcoidosis patients were also similar to those found in previous studies [9].

Manifestations of sarcoidosis are known to differ between races and genders [10,27-30,34-40]. Men with sarcoidosis tend to have higher rates of cardiac and pulmonary involvement, whereas women have a higher prevalence of peripheral lymph node involvement, cutaneous, musculoskeletal, liver, spleen and ocular involvement [10,30,34-38]. Furthermore, hypercalcaemia tends to be more prevalent in men [38]. In the Dutch neurosarcoidosis sample studied, the prevalence of various neurosarcoidosis manifestations did not differ between genders, except for peripheral polyneuropathy which was more common in men than in women (21.1\% versus $9.6 \%$ ). This finding is in line with other auto-immune polyneuropathies [41-45], in contrast to diabetic polyneuropathy, where no gender differences were found [46]. The explanation for this finding remains unclear.

As regards race, the ACCESS study, a large case-control study of sarcoidosis, found that patients of African descent were more likely to have cutaneous involvement, as well as erythema nodosum, extrathoracic lymph node, ocular, liver and bone marrow involvement, while Caucasians were more likely to develop hypercalcemia and spleen involvement $[10,39]$. In a selfreported organ involvement registry, Baughman et al. did not find differences in the prevalence of neurosarcoidosis in general between genders or races [11]. In our neurosarcoidosis sample patients of African descent appeared to be overrepresented (21\%) in comparison with the general Dutch population (4\%) This might be explained by the fact that the population in urban areas of the Netherlands (the west of the country [including Amsterdam]) and to a lesser extent the centre (e.g. Nieuwegein) includes more people of non-Dutch origin, causing bias in the racial distribution in our cohort. Moreover, patients of African descent have a higher risk of developing a more chronic severe course of sarcoidosis. However, no differences between races were found in our neurosarcoidosis sample regarding the prevalence of the various neurosarcoidosis manifestations.

Differences between races and genders regarding the various manifestations of sarcoidosis need to be considered in the management of this disorder. One of the main difficulties in accurately identifying patients at risk of progressive major organ damage and death is the heterogeneity of its presentation. Thus, the optimal risk stratification strategy in the general sarcoidosis population continues to be unclear [47]. The identification of patients at higher risk of eventual major organ involvement, in order to initiate timely treatment to prevent progression, remains a clinical challenge. The integration of clinical symptoms, results of functional and imaging examinations, and observed disease behaviour in the definition of severe sarcoidosis seems to be the most comprehensive approach suggested to date [48]. Studies in the United States found sarcoidosis mortality to be related to both race and gender, perhaps reflecting genetic factors. AfricanAmerican individuals and women had a worse prognosis, with a higher prevalence of extra-pulmonary organ involvement and prolonged disease duration, and a higher rate of sarcoidosisrelated hospitalizations [27-29,49]. Sarcoidosis patients of African descent also had a higher mortality rate than Caucasians and were treated more often $[10,29]$. In a large neurosarcoidosis study by 
Joubert et al. ( $n=234)$, no differences in mortality rates were found between various ethnicities [16]. The mortality difference between Caucasians and patients of African descent with sarcoidosis is thus explained by other sarcoidosis manifestations than neurosarcoidosis, for instance pulmonary hypertension and cardiac and more advanced pulmonary sarcoidosis $[10,29,47]$.

The majority of patients in the studied Dutch neurosarcoidosis sample needed treatment (93\%). This underlines that treatment is mandatory for neurosarcoidosis, and in many cases secondor third-line treatment is required (53\%). Considering this, plus the high relapse rate necessitating long-term treatment for neurosarcoidosis and the many side-effects of corticosteroids $[16,33,50,51]$, second- or third-line agents (methotrexate, azathioprine, or TNF-alpha inhibitors) are preferable as the firstchoice treatment in selected neurosarcoidosis cases, especially in patients with comorbidities such as obesity or diabetes. Based on clinical experience with other sarcoidosis manifestations and previous studies, second-line treatment with azathioprine and methotrexate can be regarded as safe and effective [52]. TNF-alpha inhibitors have shown efficacy and safety for both sarcoidosis in general and neurosarcoidosis [23,53-60]. Moreover, lower relapse rates of neurosarcoidosis have been described with infliximab and methotrexate $[16,33]$, as well as high relapse rates of sarcoidosis and neurosarcoidosis after discontinuation of infliximab. Thus, the decision to discontinue should be made very carefully and long-term continuation should be considered [23,53,54,61,62]. Previously, treatment with TNF-alpha inhibitors led to high health care costs. The expiring of the patent of Remicade ${ }^{\circledR}$ (Infliximab) and the availability of biosimilars (Inflectra ${ }^{\circledR}$ ) with similar efficacy have now reduced the costs [63].

Our study had several limitations. Despite significant advances in diagnostics of neurosarcoidosis made in the last two decades, no consensus has been achieved about its classification. We used the most widely used modified Zajicek criteria. Follow-up of neurosarcoidosis is difficult, since no sensitive and specific biomarker is available so far. Disease assessment is often based on symptoms and neurologic examination, sometimes combined with follow-up cerebral or spinal CTs (when applicable), making it hard to assess whether the disease is truly in remission. Another limitation could be a selection bias, since most of our patients were diagnosed and treated in tertiary expertise centres. However, patients with suspected neurosarcoidosis are usually

\section{References}

1 Arkema EV, Grunewald J, Kullberg S, Eklund A, Askling J (2016) Sarcoidosis incidence and prevalence: a nationwide register-based assessment in Sweden. Eur Respir J 48: 1690-1699.

2 Thomas KW, Hunninghake GW (2003) Sarcoidosis. JAMA 289: 33003303.

3 Durel CA, Marignier R, Maucort-Boulch D, Iwaz J, Berthoux E, et al. (2016) Clinical features and prognostic factors of spinal cord sarcoidosis: A multicenter observational study of 20 biopsy-proven patients. J Neurol 263: 981-990.

4 Gerke AK, Hunninghake G (2008) The immunology of sarcoidosis. Clin Chest Med 29: 379-390. referred to such expertise centres because of the complexity of diagnosing and treating this rare disease entity. Another limitation is the observational nature of our study, with some missing values and no structured monitoring and follow-up. Since neurosarcoidosis is a rare sarcoidosis manifestation, however, it is difficult to perform studies with another study design.

\section{Conclusion}

In conclusion, chronic aseptic meningitis, cranial nerve dysfunction, spinal cord involvement and cerebral parenchymal disease appeared to be the most common neurosarcoidosis manifestations, without racial or gender differences. Treatment was mandatory in the majority of patients, $>50 \%$ of whom required second- or third-line treatment. The current risk stratification strategy to identify severe neurosarcoidosis patients involves a multidisciplinary approach integrating symptoms, functional tests and imaging findings. Future studies are warranted to enhance our understanding of the diversity of neurosarcoidosis, the determinants of morbidity, severity and mortality, as well as optimal treatment regimens, in order to determine the best treatment to improve the quality of life of patients suffering from this rare form of sarcoidosis.

\section{Acknowledgements}

We would like to thank Esther van Noort and Curavista for providing and maintaining the website: www.neurosarcoidose.nl.

\section{Funding}

This study was supported by a research grant from the Netherlands Organization for Health Research and Development, ZonMw (Project number 842002005) and ild care foundation as well as the Dutch Sarcoidosis Society (Sarcoidose.nl). The study sponsors had no involvement in the study design, in the collection, analysis, and interpretation of data, in the writing of the manuscript or in the decision to submit the manuscript for publication.

\section{Conflict of Interest}

On behalf of all authors, the corresponding author states that there is no conflict of interest.

5 Drent M, Lower EE, De Vries J (2012) Sarcoidosis-associated fatigue. Eur Respir J 40: 255-263.

6 Statement on sarcoidosis (1999) Joint Statement of the American Thoracic Society (ATS), the European Respiratory Society (ERS) and the World Association of Sarcoidosis and Other Granulomatous Disorders (WASOG) adopted by the ATS Board of Directors and by the ERS Executive Committee, February 1999. Am J Respir Crit Care Med 160: 736-755.

7 Drent M, Strookappe B, Hoitsma E, De Vries J (2015) Consequences of Sarcoidosis. Clin Chest Med 36: 727-737.

8 Valeyre D, Prasse A, Nunes H, Uzunhan Y, Brillet PY, et al. (2014) Sarcoidosis. Lancet 383: 1155-1167. 
9 Fritz D, Van de Beek D, Brouwer MC (2016) Clinical features, treatment and outcome in neurosarcoidosis: systematic review and meta-analysis. BMC Neurol 16: 220.

10 Judson MA, Boan AD, Lackland DT (2012) The clinical course of sarcoidosis: presentation, diagnosis, and treatment in a large white and black cohort in the United States. Sarcoidosis Vasc Diffuse Lung Dis 29: 119-127.

11 Baughman RP, Culver DA, Judson MA, Gerke AK, Spitzer G (2018) Selfreported organ involvement in sarcoidosis: results of a multinational registry. American Journal of Respiratory and Critical Care Medicine 197: A7482.

12 Ungprasert P, Crowson CS, Matteson EL (2017) Characteristics and Long-Term Outcome of Neurosarcoidosis: A Population-Based Study from 1976-2013. Neuroepidemiology 48: 87-94.

13 Iannuzzi MC, Rybicki BA, Teirstein AS (2007) Sarcoidosis. N Engl J Med 357: 2153-2165.

14 Joseph FG, Scolding NJ (2007) Sarcoidosis of the nervous system. Pract Neurol 7: 234-244.

15 Marangoni S, Argentiero V, Tavolato B (2006) Neurosarcoidosis. Clinical description of 7 cases with a proposal for a new diagnostic strategy. J Neurol 253: 488-495.

16 Joubert B, Chapelon-Abric C, Biard L, Saadoun D, Demeret S, et al. (2017) Association of prognostic factors and immunosuppressive treatment with long-term outcomes in neurosarcoidosis. JAMA Neurol 74: 1336-1344

17 Pawate S, Moses H, Sriram S (2009) Presentations and outcomes of neurosarcoidosis: a study of 54 cases. QJM 102: 449-460.

18 Fritz D, Voortman M, Van de Beek D, Drent M, Brouwer MC (2017) Many faces of neurosarcoidosis: from chronic meningitis to myelopathy. Curr Opin Pulm Med 23: 439-446.

19 Joseph FG, Scolding NJ (2009) Neurosarcoidosis: A study of 30 new cases. J Neurol Neurosurg Psychiatry 80: 297-304.

20 Shah R, Roberson GH, Cure JK (2009) Correlation of MR imaging findings and clinical manifestations in neurosarcoidosis. AJNR Am J Neuroradiol 30: 953-961.

21 Stern BJ, Krumholz A, Johns C, Scott P, Nissim J (1985) Sarcoidosis and its neurological manifestations. Arch Neurol 42: 909-917.

22 Zajicek JP, Scolding NJ, Foster O, Rovaris M, Evanson J, et al. (1999) Central nervous system sarcoidosis: Diagnosis and management. QJM 92: 103-117.

23 Cohen AF, Bouvry D, Galanaud D, Dehais C, Mathey G, et al. (2017) Long-term outcomes of refractory neurosarcoidosis treated with infliximab. J Neurol 264: 891-897.

24 Leonhard SE, Fritz D, Eftimov F, Van der Kooi AJ, Van de Beek D, et al. (2016) Neurosarcoidosis in a Tertiary Referral Center: A CrossSectional Cohort Study. Medicine (Baltimore) 95: e3277.

25 Langrand C, Bihan H, Raverot G, Varron L, Androdias G, et al. (2012) Hypothalamo-pituitary sarcoidosis: A multicenter study of 24 patients. QJM 105: 981-995.

26 Scott TF, Yandora K, Valeri A, Chieffe C, Schramke C (2007) Aggressive therapy for neurosarcoidosis: long-term follow-up of 48 treated patients. Arch Neurol 64: 691-696.

27 Gerke AK, Judson MA, Cozier YC, Culver DA, Koth LL (2017) Disease burden and variability in sarcoidosis. Ann Am Thorac Soc 14: S421-S428.
28 Kirkil G, Lower EE, Baughman RP (2018) Predictors of mortality in pulmonary sarcoidosis. Chest 153: 105-113.

29 Mirsaeidi M, Machado RF, Schraufnagel D, Sweiss NJ, Baughman RP (2015) Racial difference in sarcoidosis mortality in the United States. Chest 147: 438-449.

30 Ungprasert P, Crowson CS, Matteson EL (2017) Influence of gender on epidemiology and clinical manifestations of sarcoidosis: a population-based retrospective cohort study 1976-2013. Lung 195 : 87-91.

31 www.neurosarcoidose.nl

32 Voortman M, Fritz D, Vogels OJM, Eftimov F, Van de Beek D, et al. (2017) Small fiber neuropathy: a disabling and underrecognized syndrome. Curr Opin Pulm Med 23: 447-457.

33 Bitoun S, Bouvry D, Borie R, Mahevas M, Sacre K, et al. (2016) Treatment of neurosarcoidosis: A comparative study of methotrexate and mycophenolate mofetil. Neurology 87: 2517-2521.

34 Brito-Zeron P, Sellares J, Bosch X, Hernandez F, Kostov B, et al. (2016) Epidemiologic patterns of disease expression in sarcoidosis: Age, gender and ethnicity-related differences. Clin Exp Rheumatol 34: 380-388.

35 Yanardag H, Pamuk ON, Karayel T (2003) Cutaneous involvement in sarcoidosis: analysis of the features in 170 patients. Respir Med 97: 978-982.

36 Lill H, Kliiman K, Altraja A (2016) Factors signifying gender differences in clinical presentation of sarcoidosis among Estonian population. Clin Respir J 10: 282-290.

37 Ungprasert P, Wetter DA, Crowson CS, Matteson EL (2016) Epidemiology of cutaneous sarcoidosis, 1976-2013: a populationbased study from Olmsted County, Minnesota. J Eur Acad Dermatol Venereol 30: 1799-1804.

38 Birnbaum AD, Rifkin LM (2014) Sarcoidosis: sex-dependent variations in presentation and management. J Ophthalmol 2014: 236905.

39 Baughman RP, Teirstein AS, Judson MA, Rossman MD, Yeager $\mathrm{H}$, et al. (2001) Clinical characteristics of patients in a case control study of sarcoidosis. Am J Respir Crit Care Med 164: 1885-1889.

40 Birnbaum AD, Oh FS, Chakrabarti A, Tessler HH, Goldstein DA (2011) Clinical features and diagnostic evaluation of biopsy-proven ocular sarcoidosis. Arch Ophthalmol 129: 409-413.

41 Chio A, Cocito D, Bottacchi E, Buffa C, Leone M, et al. (2007) Idiopathic chronic inflammatory demyelinating polyneuropathy: an epidemiological study in Italy. J Neurol Neurosurg Psychiatry 78: 1349-1353.

42 Lunn MP, Manji H, Choudhary PP, Hughes RA, Thomas PK (1999) Chronic inflammatory demyelinating polyradiculoneuropathy: a prevalence study in south east England. J Neurol Neurosurg Psychiatry 66: 677-680.

43 Mygland A, Monstad P (2001) Chronic polyneuropathies in VestAgder, Norway. Eur J Neurol 8: 157-165.

44 Rotta FT, Sussman AT, Bradley WG, Ram Ayyar D, Sharma KR, et al. (2000) The spectrum of chronic inflammatory demyelinating polyneuropathy. J Neurol Sci 173: 129-139.

45 Chandra SR, Karru VR, Mukheem MMA, Ramakrishnan S, Mahadevan A (2018) Immune-mediated Neuropathies Our Experience over 3 Years. J Neurosci Rural Pract 9: 30-35

46 Aslam A, Singh J, Rajbhandari S (2015) Prevalence of painful diabetic neuropathy using the self-completed Leeds assessment of 
neuropathic symptoms and signs questionnaire in a population with diabetes. Can J Diabetes 39: 285-295.

47 Walsh SWA, Kouranos V (2018) Why do people die from sarcoidosis? Curr Opin Pulm Med 24: In Press.

48 Kouranos V, Jacob J, Wells AU (2015) Severe sarcoidosis. Clin Chest Med 36: 715-726.

49 Tukey MH, Berman JS, Boggs DA, White LF, Rosenberg L, et al. (2013) Mortality among African American women with sarcoidosis: data from the Black Women's Health Study. Sarcoidosis Vasc Diffuse Lung Dis 30: 128-133.

50 Khan NA, Donatelli CV, Tonelli AR, Wiesen J, Ribeiro NML, et al. (2017) Toxicity risk from glucocorticoids in sarcoidosis patients. Respir Med 132: 9-14.

51 Broos CE, Poell LHC, Looman CWN, In 't Veen J, Grootenboers M, et al. (2018) No evidence found for an association between prednisone dose and FVC change in newly-treated pulmonary sarcoidosis. Respir Med 138S: S31-S37.

52 Vorselaars ADM, Wuyts WA, Vorselaars VMM, Zanen P, Deneer VHM, et al. (2013) Methotrexate vs azathioprine in second-line therapy of sarcoidosis. Chest 144: 805-812.

53 Chintamaneni S, Patel AM, Pegram SB, Patel H, Roppelt H (2010) Dramatic response to infliximab in refractory neurosarcoidosis. Ann Indian Acad Neurol 13: 207-210.

54 Gelfand JM, Bradshaw MJ, Stern BJ, Clifford DB, Wang Y, et al. (2017) Infliximab for the treatment of CNS sarcoidosis: A multi-institutional series. Neurology 89: 2092-2100.
55 Moravan M, Segal BM (2009) Treatment of CNS sarcoidosis with infliximab and mycophenolate mofetil. Neurology 72: 337-340.

56 Sodhi M, Pearson K, White ES, Culver DA (2009) Infliximab therapy rescues cyclophosphamide failure in severe central nervous system sarcoidosis. Respir Med 103: 268-273.

57 Wijnen PA, Cremers JP, Nelemans PJ, Erckens RJ, Hoitsma E, et al. (2014) Association of the TNF-alpha G-308A polymorphism with TNF-inhibitor response in sarcoidosis. Eur Respir J 43: 1730-1739.

58 Vorselaars AD, Crommelin HA, Deneer VH, Meek B, Claessen AM, et al. (2015) Effectiveness of infliximab in refractory FDG PET-positive sarcoidosis. Eur Respir J 46: 175-185.

59 Judson MA, Baughman RP, Costabel U, Flavin S, Lo KH, et al. (2008) Efficacy of infliximab in extrapulmonary sarcoidosis: results from a randomised trial. Eur Respir J 31: 1189-1196.

60 Hostettler KE, Studler U, Tamm M, Brutsche MH (2012) Long-term treatment with infliximab in patients with sarcoidosis. Respiration 83: 218-224.

61 Vorselaars AD, Verwoerd A, Van Moorsel CH, Keijsers RG, Rijkers GT, et al. (2014) Prediction of relapse after discontinuation of infliximab therapy in severe sarcoidosis. Eur Respir J 43: 602-609.

62 Panselinas E, Rodgers JK, Judson MA (2009) Clinical outcomes in sarcoidosis after cessation of infliximab treatment. Respirology 14 522-528.

63 Schimmelpennink MC, Vorselaars ADM, Van Beek FT, Crommelin HA, Deneer VHM, et al. (2018) Efficacy and safety of infliximab biosimilar Inflectra((R)) in severe sarcoidosis. Respir Med 138S: S7-S13. 